\title{
PUREZA Y FIDELIDAD VERSUS CORRUPCIÓN Y COHECHO. EL EJEMPLO DEL EMBARGO GENERAL DE 1598
}

\author{
Alfonso Rodríguez Grajera \\ Universidad de Extremadura
}

\begin{abstract}
RESUMEN. El buen fin de cualquier iniciativa pública dependía de la adecuada selección de quienes habían de ejecutarla. Los ministros reales debían estar cualificados y ser honestos y leales. Ignorancia, infidelidad y deslealtad se consideraban causa del fracaso. La actuación del Auditor de galeras durante el embargo general de 1598 es un ejemplo de cómo las malas prácticas condicionaron, junto a otros factores, el éxito de esta iniciativa.
\end{abstract}

Palabras clave: capacidad, lealtad, fidelidad, prohibición, embargo.

ABstract. The good end of any public initiative depended on the proper selection of those who had to execute it. The royal ministers must be qualified and honest and loyal. Ignorance, infidelity and disloyalty were considered cause of failure. The performance of the Auditor of galleys during the general embargo of 1598 is an example of how bad practices conditioned, along with other factors, the success of this initiative.

Keywords: Capacity, Loyalty, Fidelity, Ban, Seizure.

\section{Introducción}

Uno de los más fieles y lúcidos servidores de la Monarquía Hispánica, Mendo da Mota Vasconcelos, consejero de Portugal desde 1614 hasta su fallecimiento en 1632 y miembro de la Junta de Comercio desde su creación, afirmó que pureza y

Recibido: 29-1-2019 • Aceptado: 2-6-20198·rguezgra@unex.es 
fidelidad eran las dos virtudes que debían adornar a los ministros reales ${ }^{1}$ (Luxán, 1989, pp. 197-228; Baltar, 1998, p. 210). Solo así podrían remediarse los males que aquejaban a la monarquía. Gran conocedor del tráfico mercantil, que como tantos otros intentó reformar sin éxito, vivió en unos años en los que la práctica de la guerra económica se había impuesto (Israel, 1996, pp. 39-48); unos tiempos en los que tanto en la corte de Madrid y de Bruselas como entre quienes tenían relación directa con la actividad comercial, se consideraba que ese era el medio más eficaz — más que la guerra tradicional, aunque sin renunciar a ella- para vencer al enemigo holandés, recuperar su obediencia y recobrar un protagonismo económico que hacía ya varias décadas había dejado de ser tal.

Los problemas, ciertamente, venían de lejos, del reinado de Felipe II, y comenzaron poco después de una revuelta que la fuerza de las armas, la intolerancia y la represión, encarnadas en la figura de Alba, no habían sido capaces de sofocar. La toma por los rebeldes de los más importantes puertos de las islas y su protagonismo en el mar no limitaron su dominio, como muy pronto se puso de manifiesto y fue evidente a todos, al plano militar, sino también y sobre todo al económico. Que una parte considerable de los desobedientes vivía del mar y que de él se obtenían los recursos que les permitían mantener una guerra que sangraba las arcas de la monarquía era una realidad a la que resultaba imposible sustraerse. Así lo ponen de relieve las quejas y demandas de un Requesens desbordado o los consejos de Granvela (Rau, 1951, p. 136). En el mismo sentido cabe interpretar los intentos de establecer relaciones con suecos, hanseáticos y polacos, que tan magros resultados procuraron ${ }^{2}$.

Aquellas iniciativas diplomáticas y la constante avalancha de discursos, memoriales y advertimientos, que llegaban a la corte desde los más diversos ámbitos (ministros y comisionados reales, militares o comerciantes), ponían el acento en la necesidad de socavar el poderío naval de los enemigos y el comercio que mantenían con los reinos hispánicos —el denominado comercio madre_-, además de la pesquería. Fueron numerosas las propuestas, los medios, que se enunciaron — básicamente para prohibirles ese comercio; también para permitírselo a cambio de gravosas condiciones fiscales - que se intentaron poner en práctica en las décadas finales del siglo XVI, con vacilaciones y contradicciones, entre prohibición y libre comercio ${ }^{3}$. Tras la Tregua,

«Que el remedio de todos estos males viene a consistir solo en la pureza y fidelidad de los ministros». Archivo General de Simancas (en adelante AGS), Estado, leg. 2847, s/f.

2 La comisión del capitán Francisco de Eraso en la corte de Juan III, las negociaciones con el rey polaco Esteban Bathory, las de Charles de Egmont con Christian IV de Dinamarca, la embajada del Almirante de Aragón ante el duque Carlos (futuro Carlos IX) y con su sobrino Segismundo III y, en fin, las emprendidas con las ciudades hanseáticas, con Hamburgo a la cabeza.

3 La propuesta del Fiscal del Almirantazgo de Amberes, Peter Opmeer, que no llegaría a implantarse y el posterior y efímero Decreto Gauna son algunos de los ejemplos más significativos. 
de un modo más sistemático y organizado; el convencimiento en las bondades de su aplicación no sería suficiente para lograr el resultado que tanto se ansiaba.

Las razones que se han aducido para explicar ese fracaso han sido de muy diverso tipo. Aunque referidas específicamente a la década final del siglo XVI, son en líneas generales, válidas para los años posteriores a 1621 (Ruiz Ibáñez, 2005, pp. 85-109). Se ha insistido en la gravedad de la crisis productiva del sur de Europa, que aumentó desde finales del siglo XVI de modo considerable la dependencia de aquellos productos, sobre todo de los de primera necesidad, navegados por los holandeses, y que facilitó y consolidó su presencia en las costas peninsulares, y más allá del estrecho de Gibraltar. Al respecto, las permisiones y licencias para traer trigo y pertrechos navales fueron numerosas. Asimismo se ha hecho hincapié en las limitaciones de una política de prohibiciones y embargos que, avalada por memorialistas, ministros y consejeros reales, se implantaría a partir de mediados de los años ochenta del siglo XVI y se afianzaría desde la década de 1630, tal y como muestran los memoriales que llegaban a la Junta de Comercio y los propios debates que se suscitaron entre las paredes de la posada del marqués de Montesclaros. No menos importancia se ha atribuido a la incapacidad de aquellos a quienes, sin éxito, se había recurrido desde los años setenta para reemplazar a holandeses y zelandeses en el transporte de todo aquello de lo que el sur de Europa carecía ${ }^{4}$. En este sentido, tras la obligada firma de la paz con Francia (Vervins, 1598) y el fracaso de la aplicación del Decreto Gauna, los tratados para el restablecimiento del comercio suscritos con Francia e Inglaterra en 1604 tenían la pretensión de garantizar la fluidez de los intercambios con unos socios de los que, además, se esperaba que al mismo tiempo contribuyeran a estrangular el comercio rebelde (Echevarría, 1985, pp. 119-142; Alloza, 2012, pp. 1-34); por ello se prohibía a los súbditos de ambos reinos:

que lleve o pase de qualquier modo, directa o indirectamente, en nombre propio o ageno, ni preste nave alguna u otro carruaje, ni su nombre, para conducir o pasar algunas naves, mercadurías, manifacturas y otras qualesquiera cosas de Holanda y Zelanda a España y a los demás reinos y dominios del rey de España y Archiduques, ni lleve en sus naves a dichas partes mercader alguno holandés y zelandés 5 .

Idéntico propósito perseguían los acuerdos rubricados en 1607 con las ciudades hanseáticas, los proveedores a quienes tradicionalmente se consideró sustitutos idóneos

Pese a disponer de una considerable flota mercante, se tenía por imposible que los hanseáticos desplazasen a los holandeses del comercio peninsular. Así lo afirmaba el anónimo autor de un memorial de finales del siglo XVI. AGS, Estado, leg. 2852.

5 Tratado de Londres, Archivo Histórico Nacional, Estado, leg. 2798, expediente 6. 
de holandeses y zelandeses ${ }^{6}$ (Gómez Centurión, 1986, pp. 65-84). Se permitía a sus súbditos el libre acceso, trato y comercio en los puertos peninsulares, sin licencias ni pasaportes, sin visitas, embargos ni otras molestias y agravios que en tantas ocasiones habían denunciado. Tampoco pagarían derechos algunos por aquellas mercancías que tanto se precisaban: «del trigo, del maderamen del que se fabrican los navíos y mástiles y antenas dellos y de las municiones militares como son mosquetes, arcabuzes, pólvora, balas de hierro y plomo». Esas concesiones tenían como lógica contrapartida la prohibición de «llevar mercancías de estos reynos a Holanda y Zelanda, sino solo a los puertos hanseáticos y a otros lugares amigos o neutrales». Se intentaba así poner fin a la tan perjudicial colaboración entre hanseáticos y rebeldes.

Se pretendía, también, hacer frente a uno de los más graves problemas, a la postre irresoluble, que impediría el éxito de las políticas mercantiles diseñadas por la corte, de las prohibiciones y embargos y, por ende, la destrucción del enemigo, el fin último perseguido. El comercio alegal, el contrabando, fruto evidente de la necesidad y de unas redes comerciales ya consolidadas, se desarrolló en paralelo a esas políticas de intolerancia, al calor de la falta de medios y de la laxitud para combatirlo. El incumplimiento de las disposiciones reales, los abusos y, en definitiva, las malas prácticas por parte de los servidores públicos — en tanto que contrarias al buen gobierno-, contribuyeron a la expansión del contrabando y también por tanto al fracaso o al limitado éxito de las distintas iniciativas que se pusieron en marcha (Andújar y Ponce, 2018, p. 11). Mendo da Mota, refiriéndose de modo específico a lo que sucedía en las costas portuguesas, donde el contrabando y los fraudes eran habituales, había hecho especial hincapié en la codicia de los ministros inferiores (Schaub, 2001; Alloza, 2009, pp. 1-18). De aquellos servidores reales destinados en los puertos, alejados de la corte y del rey, poco o nada celosos del real servicio y con frecuencia mal pagados. Cambiar esa dinámica había sido un empeño largamente perseguido contra el que no surtiría efecto la imposición de penas con las que serían castigados los transgresores. En este sentido, su severidad pone de manifiesto la preocupación que este problema suscitaba: a los administradores, aduaneros y otros oficiales que «disimularen» en la supervisión de las mercancías que llegaban a los puertos castellanos se les sancionaría con la pérdida del oficio y 20.000 maravedíes. A quienes encubrieren o actuasen con malicia, con la privación perpetua del oficio y 100.000 maravedíes. Penas aún mayores se establecían para aquellos que no llevasen las mercancías a las aduanas ni las registrasen para evitar así el pago de los derechos reales:

Capítulos de privilegios concedidos a las ciudades confederadas de la Hansa Teutónica y a sus súbditos, ciudadanos y vecinos en los dominios de Portugal, confirmados y ampliados por su Majestad católica para la Andaluzía y demás reynos de Castilla, Madrid, 28 de septiembre de 1607. 
a los que así lo hicieren y se les probare, aunque no los encuentren en fragante con las tales mercaderías [...] si fueren de las prohibidas, demás de perdellas y las que con ellas fueren, incurran en pena de destierro del reino por seis años y 200.000 maravedíes?

\section{Cómo evitar malas prácticas}

Las advertencias, fruto de recelos acreditados por la experiencia, eran el complemento de la prevención — no satisfecha - que se pretendió imponer en la elección de ministros y comisionados reales. Los consejos que en este sentido se dieron fueron tan numerosos como homogéneos. Su reiteración no es sino una manifestación de que fueron sistemáticamente ignorados, o de imposibilidad de ponerlos en práctica. En el exhaustivo informe que Esteban de Ibarra elaboró para el archiduque Alberto a su llegada a la gobernación de Flandes, el secretario de Estado y Guerra hacía referencia a las malas prácticas — sustanciadas en una disciplina que calificaba de ruin y una distribución de los recursos realizada con mala traça - habidas durante la gobernación de Parma, cuya actuación debía fiscalizar, las cuales eran la causa fundamental de los problemas por los que atravesaba la Armada de Flandes ${ }^{8}$. Lo atribuía a la malicia o a la ignorancia — más a ésta que a aquella — de los ministros responsables; también, a la «codicia de unos y al descuido de otros». La solución que proponía pasaba en primer lugar por situar en los puestos de responsabilidad a individuos capacitados, porque el mérito y la profesionalidad fueran los criterios que rigiesen los nombramientos, al contrario de lo que había sucedido en la etapa de Farnesio. Los conocimientos y la diligencia no eran, sin embargo, suficientes. A ellos debían unirse la fidelidad y la honestidad, atributos que para Ibarra solo podían recaer en los españoles, no en los ministros flamencos, de quienes no fiaba. Capacidad y fidelidad serán, pues, dos requisitos esenciales para garantizar el éxito de la guerra económica en la que ya desde las últimas décadas del XVI se había embarcado la monarquía. Y asegurarse esas cualidades dependía asimismo de señalarles un sueldo justo, competente y suficiente para su mantenimiento.

A lo largo de ese tiempo en el que se mantuvo el enfrentamiento y se sucedieron las propuestas para acabar con el comercio holandés, dos ideas se repitieron en memoriales, discursos y debates con machacona insistencia. Para lograrlo era necesario, de una parte, que las prohibiciones decretadas se cumplieran, que se les cerrasen todas las vías de acceso al enemigo, sin ningún tipo de fisuras ni concesiones. De otra, que a los

AGS. Estado, leg. 2847.

Ibidem, leg. 612, expediente 122. 
amigos y neutrales se les dispensase buen trato, se les evitasen molestias y agravios y se les facilitase de este modo la contratación. Y como mantenía Ibarra, de ejecutarlo debían encargarse individuos cualificados, fieles y bien remunerados; unos individuos que eran parte fundamental del engranaje que conduciría a una victoria que tanto se resistía. Por el contrario, la inadecuada elección de aquellos que habían de ser «los pies y las manos por quien esta materia tan grave se maneja», su falta de compromiso e implicación en el real servicio, su deslealtad y, también, la escasa retribución que por el desempeño de sus funciones recibiesen, precipitaría el fracaso. Y el temor a ese fracaso no era infundado De ahí lo indispensable que resultaba nombrar ministros adornados por esas cualidades.

A finales de 1598, antes de iniciar su comisión en las costas andaluzas tras el embargo decretado por Felipe III al poco de acceder al trono, Joachim Butquens, el mercantilista holandés enviado por el archiduque Alberto a la corte de Madrid con el propósito de poner en marcha un embargo general, volvía a reiterar, una vez más, aquello en lo que tanto insistió en los numerosos escritos que sin descanso había dirigido a Felipe II: para que la prohibición del comercio a los rebeldes fuese realmente efectiva, tal como se pretendía, había que controlar de modo exhaustivo el tráfico mercantil entre el norte y el sur de Europa (Rodríguez Grajera, 2015, pp. 1809-1842). Y para hacerlo era preciso desplegar agentes - guardas - encargados de visitar los navíos y examinar mercancías y pasaportes en los puertos españoles y, también, en los bálticos y en los de las provincias obedientes de los Países Bajos. Una idea que no resultaba ni novedosa ni original, y que Butquens hizo suya, desarrolló y perfeccionó ${ }^{9}$ Quienes recibieran esos encargos debían poseer amplios conocimientos sobre la actividad mercantil, tener experiencia en la práctica del comercio y de navegación (con amigos y enemigos) y ser versados en las lenguas, dialectos y aspiros del norte de Europa, así como en las costumbres y modo de vida de los naturales de aquellas tierras. Solo con esa cualificación estarían en condiciones de tener éxito en la misión que se les encomendaría. A ese cúmulo de conocimientos había de añadirse un requisito más. Butquens proponía que quienes hubieran de ocuparse de tal cometido en los puertos peninsulares no fueran, al contrario de lo que mantenía Ibarra pero por las mismas razones, españoles, sino naturales de los Países Bajos. Y el argumento que aducía para ello no solo residía en su notoria dificultad para expresarse en las lenguas del norte - que no entendían y podían ser fácilmente engañados por los intérpretes-, sino en asegurarse unas lealtades que en el caso de los peninsulares no dudaba

En el mismo sentido y con idénticos argumentos se había expresado unos años antes su compatriota Peter Opmeer. AGS, Estado, leg. 614, expedientes 159, 160 y 161, leg. 607, expediente 239. El proyecto de Joachim Butquens contaba con la aprobación del Consejo del Almirantazgo de Amberes y del propio Archiduque. 
en cuestionar. Los flamencos, decía, no se dejarían cohechar tan fácilmente como lo hacían los españoles. Así lo había puesto de manifiesto ya en 1596 cuando afirmó que «mejor se castiga en Flandes estos traydores y no tienen el favor que tienen por acá, por el interés particular» ${ }^{10}$. La honestidad aparecía como requisito imprescindible para el éxito de su propuesta. El mismo sentido tenía su insistencia en conseguir que las justicias locales — en quienes distaba de confiar - se inhibiesen en todo lo relacionado con embargos, confiscaciones, presas y mercancías. No olvidaba, por supuesto, que llevasen a modo de salario un derecho de visita sobre los navíos, que estipulaba suficiente en dos reales por tonelada.

Las afirmaciones de Butquens no eran en modo alguno gratuitas ni respondían, pese a la altivez y arrogancia que caracterizaban al personaje, a un cierto desprecio hacia quienes no eran flamencos. Eran la manifestación más cruda y directa de un problema del que, al igual que Ibarra, era plenamente consciente. Un problema que no se solventaría pese a los continuos llamamientos para lograrlo. En este sentido, las denuncias por el incumplimiento de los acuerdos que se habían suscrito comenzaron inmediatamente después de firmada la paz de Vervins, a finales del siglo XVI, tras el embargo general de 1598. Pedro de Zubiaur advertía en noviembre de ese año de una práctica ya entonces habitual en las costas andaluzas: navíos de amigos y neutrales - sobre todo franceses, por quienes sentía una notoria aversión - llevaban las mercancías peninsulares a puertos rebeldes. Solicitaba que para evitarlo se les exigieran fianzas de no descargarlas en tierras de enemigos ${ }^{11}$. También don Luis de Peñalosa, comisionado para el embargo en los puertos onubenses, señalaba que en ellos se cargaban mercancías - vino, sobre todo - fingiendo ser para venderlas en Portugal y, desde allí, con la complicidad de los naturales - y con una vigilancia mucho más laxa - se dirigían a tierras rebeldes. Afirmaba asimismo que muchos navíos salían de puerto sin especificar el destino de su carga, tal como era obligado, gracias a que los encargados de verificarlo «los dejan pasar por cualquier cosa de interés que les den» ${ }^{12}$. Eran por tanto esos ministros inferiores, a los que se referiría años más tarde Mendo da Mota, quienes más fácilmente se dejaban corromper y con su actitud impedían que los esfuerzos y desvelos de leales servidores, como lo era don Luis, fueran recompensados ${ }^{13}$.

Ibídem, expediente 103.

11 Don Alonso de Velasco, veedor general de las galeras de España y comisionado para el embargo en los puertos andaluces, hacía hincapié en que el celo que se ponía en no agraviar a neutrales y amigos no había logrado romper la colaboración que mantenían con los rebeldes. La denuncia de Zubiaur lo corroboraba. AGS, Guerra y Marina, leg. 561, expediente 79.

$12 \quad$ Ibídem, expediente 72.

13 Poco después, en 1599, Juan de Gauna, en su memorial sobre el tráfico de la sal, había advertido de la necesidad de situar en los puertos a personas de «confianza», para asegurar un estricto control de los intercambios. Ibídem, leg. 616, fols. 181 y ss. 
Pero la realidad no era tan simple y el problema se había extendido hasta convertirse en un mal generalizado que no se limitaba, nunca lo había hecho en realidad, a los últimos eslabones de la cadena; estaba presente en todos ellos. Son numerosos los testimonios que ponen de manifiesto la magnitud que alcanzaría cuando la guerra económica se tornó en la principal arma de la monarquía para someter a los rebeldes. Dos años después de finalizada la Tregua se vio en la Junta de Comercio una carta del cántabro Tomás de Ibio Calderón, quien desde Cádiz lo planteaba en estos términos:

si Su Majestad tuviese ministros fieles y que tomasen el trabajo que deben en hazer sus oficios en las aduanas por su mano y de las personas que pueden ocupar, se justificará puramente lo que se desea, pero lo cierto es que ninguno de quantos servimos a Su Majestad cumplimos con una parte sola de nuestra obligación, siendo esto la misma verdad; de qué sirve quanto se propone ni quanto se dispone y se manda, ninguna orden de Su Majestad se cumple de ninguna manera, ni se castiga a nadie, todos hallan ángel de guardia; esto va consumiendo estos reynos ${ }^{14}$.

La denuncia de Ibio, que no rehuía la autocrítica, ponía de relieve los fallos en la cadena de mando, la flagrante falta de control por parte de los responsables políticos $\mathrm{y}$, en consecuencia, el incumplimiento generalizado de las obligaciones contraídas, además de la nula capacidad de reacción para atajar el problema y, también, la existencia de una estructura organizada que amparaba y protegía a quienes delinquían, convirtiendo en papel mojado apercibimientos y avisos. El resultado de esa situación era la absoluta ineficacia de las disposiciones reales. No era consuelo ni remedio que aquellos que podían solventarlo y no lo hacían dieran «muy estrecha quenta» a Dios, como aseguraba lo harían. Con independencia de lo que las palabras del contador y veedor general de la Armada del Mar Océano pudieran tener de exageración, lo cierto es que el único medio que contemplaba para garantizar la correcta aplicación de las políticas reales era asegurarse previamente la fidelidad de quienes estaban encargados de ejecutarlas. De ello estaban convencidos todos cuantos presentaron algún proyecto para acabar con el comercio rebelde. Entre ellos Manuel López Pereira, uno de los hombres con más experiencia en este campo y autor de varios memoriales en los que planteaba la creación de compañías privilegiadas al modo de las holandesas, para competir con sus mismas armas (Israel, 1985, pp. 109-126; Alloza y Cárceles de Gea, 2009). En un papel que se vio en la Junta de Comercio el 9 de agosto de 1623, desde su «experiencia costosa en las tierras rebeldes», realizaba un documentado análisis del tráfico mercantil del norte de Europa, de las mercancías que llegaban hasta la península desde aquellas tierras y de los medios que debían ponerse en práctica para 
discriminar las de enemigos de las de amigos y neutrales - certificaciones, licencias, registros, visitas e inspecciones, establecimiento de almacenes, etc.- - para garantizar el castigo de aquellos y la libre contratación de estos. Después de lo cual advertía que:

todo consiste en poner en las aduanas personas de buena consciencia y verdad, porque poco aprovecha prevenir si la que lo ha de executar no mira a otra cosa que a su provecho particular, de que se verná a seguir que en lugar de prohibir lo que se pretende, recambiará todo en beneficio de los contrarios, que sin pagar derechos meterán todas sus mercadorías y se harán maiores ganancias ${ }^{15}$.

López Pereira no era optimista respecto a las posibilidades de encontrar individuos que reunieran esas cualidades. Es más, no creía que «se pueda remediar este inconveniente». Y si la alternativa era mantener una situación que tan gravosa resultaba para las arcas reales, se mostraba partidario de «permitir que [los holandeses] puedan entrar libremente en sus propias naos», aunque poniendo los medios para que eso no signifique mostrar signos de «flaqueza» ni conlleve pérdida de reputación.

Fue mucho lo que se debatió en la Junta de Comercio sobre la conveniencia de establecer un libro de registro y manifestaciones en los puertos peninsulares ${ }^{16}$. Un libro en el que se anotase «la salida con la entrada de las mercaderías de los estrangeros y las de los naturales recíprocamente, de modo que tanto va lo que saquen en cosechas de la tierra como metieren». Era el remedio que proponía el proveedor Ortuño de Urízar para evitar uno de los mayores problemas de la economía hispánica, la saca de moneda del reino. Una medida cuyo éxito fiaba a las «buenas personas que lo han de executar y encaminar», a la adecuada elección de estos «porteros que abran y cierren las puertas de la mar», cinco personas de confianza establecidos en los puertos de Lisboa, Sanlúcar, Bilbao, San Sebastián y Málaga. Años antes, en las instrucciones que se dieron al veedor del comercio en Flandes, Antonio de Jaúregui, se insistía en la necesidad de poner allí una «persona de mucha confianza», encargada de revisar las mercancías.

La correcta selección de los ministros fue asimismo una preocupación constante de los miembros de la Junta de Comercio. Con ocasión del debate sobre la utilidad de disponer en los puertos de Hamburgo y Dunquerque de agentes de la monarquía encargados de registrar las mercancías que desde el Báltico y los Países Bajos obedientes se

Ibidem.

16 El establecimiento de este libro se había suspendido a comienzos del siglo XVII, al entrar en vigor el Decreto Gauna. En la Junta de Gobierno se ignoraba en qué puertos existía ni quiénes estaban a su cargo. El marqués de Montesclaros propuso en febrero de 1624 se «escriba a todas partes preguntando si hay este libro [...] quién tiene este libro y cómo se usa del y por qué orden fueron nombradas las personas que le tienen». Se intentaba así poner remedio a una evidente falta de control que fomentaba el desorden y alentaba la desobediencia. 
navegasen hacia el sur, y de un tercero que en la corte se correspondiese con ambos, se reitera que debían ser personas «de la integridad e inteligencia que se requiere, pues en esto consiste todo el efecto de este negocio». Si esas personas no fuesen legales, «todo el trabajo que se toma sería en vano». Experiencia, celo, entereza, de muy buenas partes, cuidadoso, plático, de calidad, de mucha rectitud, de satisfacción, buena persona. Esas son las cualidades que reiteradamente se buscan en quienes han de servir y en cuyas manos se fía. El buen hacer con el que se ha servido en oficios anteriores también era considerado un argumento decisivo para valorar la aptitud de quienes se postulaban para futuros desempeños. En este sentido, la coincidencia con el lenguaje de las sentencias por residencias es prácticamente total (Barrientos, 2018, p. 83).

Todas esas cualidades se resumen en una carta que creemos enviada desde las costas portuguesas y dirigida a don Fernando Alvia de Castro, veedor general de la gente de guerra de Portugal. Datada en 1623, su autor, que no conocemos, preocupado por la actitud de los guardas que en los puertos lusos se encargaban de velar por el cumplimiento de las órdenes reales y evitar fraudes, glosa las virtudes que han de tener ministros y servidores reales ${ }^{17}$. Afirma que el único remedio — «primer fundamento y cimiento seguro»- de todos los daños y para que las medidas que se tomen sean efectivas no es otro que «el de darse los oficios a los hombres de mayor celo e inteligencia que se pudieren hallar, y estos se han de buscar con grande cuydado, sin aguardar a que ellos los pidan». No duda el autor en manifestar una más que velada crítica a los modos con los que se procedía a efectuar los nombramientos: «si estas ocupaciones no se dan por mérito, sino al pariente y al amigo, que nunca vio ni entendió lo que se le encarga, qué quenta dará de ello [muy mala] ». Celoso, inteligente y libre de codicia; esas son las tres cualidades que ha de reunir quien se ocupe de servir a su rey:

aunque tenga celo no le sirve de nada sin inteligencia, y la inteligencia y el celo de menos si no tiene limpieza, pruebase que en no estando el criado de Su Majestad adornado de estas tres cosas no puede dar buena quenta de lo que se le encarga, y los que le asisten andan mirando con gran cuydado por qual de las partes le podrán acometer, y en hallándole sin alguna de las tres referida, allí asestan la artillería, y es cosa muy llana que con lo que se pierde por descuidos de ministros de SM y mala administración en la hazienda y derechos reales, pudiera ser un rey gran rey.

No olvidaba mencionar la importancia de que esos ministros inferiores recibiesen por su trabajo un salario justo, «con que se puedan sustentar», que estimaba en 300 ducados anuales, suficiente para evitar «hacer cosa ruin». Una recomendación tan habi-

«Los daños que se siguen en las aduanas y por mano de las guardas que los ministros de ellas ponen en las naos que vienen con mercadurías». AGS, Estado, leg. 2847. 
tual, tan reiterada, que no era sino un reproche a la práctica común de recompensarlos únicamente «los días que se ocupan, y una cosa muy limitada». En esas condiciones, no resultaba extraño que la connivencia y el cohecho resultasen tan frecuentes como imposibles de erradicar.

Cabe preguntarse, ante tal reiteración en tan distintos foros y por voces tan cualificadas para intentar evitar la comisión de delitos, por la incidencia que la calidad de ministros y comisionados tenía en el buen fin de lo que se pretendía; hasta qué punto la inadecuada elección de los servidores, la deslealtad, la infidelidad, la codicia, la falta de preparación y de compromiso, amén de los obstáculos y dificultades para perseguir y castigar esas conductas, condicionaron los resultados de las políticas diseñadas para combatir, por medios económicos, al enemigo. Fraudes, estafas, desfalcos, extorsiones, abusos de poder, excesos y otros delitos, cometidos por quienes tenían la obligación y la responsabilidad de cumplir y hacer cumplir la ley, fueron prácticas habituales que podemos catalogar como corruptas. Con independencia de la valoración y el alcance que otorguemos al término corrupción en las sociedades de Antiguo Régimen, su estudio se ha convertido en un tema de interés historiográfico ${ }^{18}$ (Andújar, Feros y Ponce, 2017, pp. 284-311). Las malas prácticas de los servidores públicos se asociaban a individuos para cuya selección no se habían aplicado los rigurosos criterios tantas veces invocados, a la dejación de responsabilidades y a coyunturas especialmente favorables para que germinasen. El estudio de casuísticas concretas nos permite, como también se ha señalado en alguna ocasión, conformar una visión global de un fenómeno de tanta importancia. Tanto más en relación con las vicisitudes de las relaciones comerciales entre la Península Ibérica y Flandes, que en el caso español se ha centrado más en el estudio de las propuestas - emanadas tanto de los escritos de memorialistas como de ministros y consejos - para evitar y perseguir el fraude que en el análisis de casos específicos. Como veremos en el ejemplo que analizamos, las consecuencias de estas acciones afectaron no solo a quienes se vieron directamente implicados y perjudicados por ellas — sus víctimas —, sino a la eficacia y credibilidad de las políticas diseñadas por la monarquía.

18 No nos referimos aquí a definiciones y conceptos de los tratadistas políticos o morales de la época, de los que Saavedra Fajardo es sin duda el ejemplo más significativo. No obstante, en sus Empresas vincula la inteligencia con el mando; es la capacidad de tomar decisiones y elegir a aquellos que mejor puedan desempeñar las funciones que se le encomiendan, para lo cual, afirmaba en la Empresa 57 que debía ajustarse «la capacidad de los sujetos a los puestos». También afirmaba, en plena coincidencia con todo lo señalado, que debía darse a los oficios «dote competente con que se sustente el que los tuviera». Aspectos fundamentales para entender el negativo impacto que se seguiría de unas actitudes no guiadas por esos principios. En un sentido más laxo, esa preocupación la entendemos como una muestra del interés por prevenir comportamientos que conducían a malograr determinadas políticas. 


\section{Corrupción en el embargo general de 1598}

Las políticas prohibicionistas, de mano dura, han sido terreno abonado para el desarrollo de prácticas delictivas en cuyo acontecer el protagonismo recaía en aquellos que habían traicionado la confianza en ellos depositada para hacerlas cumplir. Tal sucedió con motivo del embargo general de navíos, mercancías y haciendas de enemigos decretado en 1598, cuando la guerra económica daba sus primeros pasos.

Un embargo que se ha considerado fue la carta de presentación de Felipe III y un auténtico tour de force belicista (Gelabert, 2007, p. 68). No obstante estaba previsto de antemano, para el mes de septiembre, «quando venga la vendeja». Así lo pone de relieve una carta fechada el 20 de agosto en Sanlúcar, por la que se ordenaba a don Alonso de Velasco, Veedor General de las galeras de España, que se encargase de embargar las naos que llegaren a los puertos de Andalucía, y que lo mismo se hiciese en los puertos portugueses, gallegos y del Cantábrico ${ }^{19}$. A todos los comisionados se les encargó el máximo secreto «hasta el efecto y la esecución con el rigor necesario», dándose unas primeras y someras instrucciones de cómo proceder. Tras los lutos por el fallecimiento de Felipe II, cuya larga y penosa enfermedad fue quizás la causa del retraso, el mencionado Alonso de Velasco recibió del joven monarca la comisión para hacerse cargo del embargo general en Andalucía; en la misma fecha, 24 de septiembre, se comunicó lo mismo al Conde de Portalegre, al Duque de Feria, al virrey de Valencia y al gobernador de Galicia, para efectuarlo en sus respectivos distritos. Se esperaba que el efecto sorpresa provocado por la coincidencia garantizase el éxito de la empresa ${ }^{20}$.

Entre las precisas instrucciones que se dictaron desde la corte, se pedía a los comisionados extremar las precauciones para detectar los fraudes, evitar perjudicar a amigos y neutrales y, también, la inhibición de las justicias locales (López Martín, 2005 , p. 4). Con estas decisiones se pretendía evitar cualquier tipo de prácticas corruptas, tanto mayores en una coyuntura crítica y en ese ámbito que constituía la última y más permeable de las fronteras, los puertos. Un escenario que - ya fuera por la escasez de medios materiales y humanos, ya por la laxitud, interesada o no, de la vigilanciaresultaba propicio para que surgiesen. En efecto, robos y pequeños hurtos estaban a la orden del día. Mercancías que habían sido embargadas, todo tipo de bastimentos e incluso efectos personales — como vestidos — de maestres y marineros detenidos eran el objetivo de delincuentes comunes — soldados y guardas encargados de custodiarlos en su mayor parte- que en ocasiones se beneficiaban del parentesco o de la

$20 \quad$ AGS. Guerra y Marina. leg. 561, expediente 31. 
relación laboral con los ministros reales ${ }^{21}$. Sin duda importantes, esos hurtos, que en buena medida se atribuían al desorden en el inventariado de las mercancías, en cierto modo inevitables, no eran lo que más preocupaba. Lo que realmente inquietaba, por cuanto ponía en riesgo el éxito del embargo y le «restaba eficacia», eran determinadas actitudes como los sobornos, las sentencias arbitrarias, la imposición de gravámenes inexistentes o el uso de la fuerza para apoderarse de todo tipo de mercancías ${ }^{22}$ (Pulido, 1993, p. 20). Comportamientos que, según Butquens, llevaban además a la pérdida de reputación de la monarquía. Por ello recomendaba que se extremase el castigo para quienes disimulasen o consintiesen, aplicándoles la ley del Talión.

Al poco de su llegada a Sevilla para hacerse cargo de la comisión que se le había encomendado, Butquens fue advertido por el presidente de la Casa de Contratación, don Bernardino de Avellaneda, y también por el Regente de la Audiencia, Pedro López de Alday, acerca de las andanzas de un personaje singular, no por completo desconocido por la historiografía, con el que habría de compartir tareas de identificación de navíos y tripulaciones enemigas (Gómez Centurión, 1988, p. 327; Rodríguez Grajera, 2015, pp. 1809-1842). Se trataba del licenciado Alcázar de Heredia, auditor de las galeras de España y Nápoles, de quien según se decía, «tiene destruido el mundo, y todo con fundamento de sacar dineros». El epicentro de sus actividades delictivas era el puerto de Sanlúcar, una población en la que según el regente, más que en ninguna otra, «se vende la justicia tan públicamente como todas las demás cosas venales». Las sospechas fueron comunicadas por Butquens a don Alonso de Velasco, quien le encargó que con todo secreto investigase esas acusaciones, con la promesa de retirar la comisión al auditor y castigarle si se demostraban ciertas.

Hombre que se definía a sí mismo como de acción — se ofreció a participar en el segundo intento de invasión de Inglaterra: «seré el primero en desembarcar»—, Butquens se vio sumido en una pesquisa, por completo ajena a su comisión, cuyos resultados esperaba poder demostrar «viéndolo por los ojos y por testimonios». Solo entonces, afirmaba, «escribiré la verdad y con fundamento». Si bien en las ocasiones que coincidió con él no manifestó queja alguna de una actitud que pudiera tacharse de reprobable, obtener la declaración de testigos que respaldasen esas imputaciones no le resultaría fácil: «nadie se atreve a deponer contra el Auditor y otros, de temor que les perseguirá injustamente». Con el poder y los medios de los que disponía, Alcázar de Heredia impuso un silencio que la promesa de mantener secretas las confidencias no

${ }_{21}$ Uno de esos delincuentes, acusado de robar seis pacas de mercaderías, era cuñado del juez encargado de sustanciar las causas del embargo en Cádiz; su cómplice, de nombre Juan del Valle, era asistente de un contador. Ambos serían detenidos.

22 El alcalde de sacas cargaba a cada navío con un impuesto de ocho ducados y medio del que Butquens decía no saber «en qué se funda ni desde cuándo». AGS, Estado, leg. 614, expediente 106. 
había logrado romper. Una red de complicidades tal que puso en serio riesgo la vida de Butquens, al que se intentó disuadir de sus indagaciones utilizando medios violentos:

han me pensado hacer un tiro en el camino del Puerto, pero yo iba apercibido de escopetas, criado y compañero, de manera que ayna llevaban la peor [...] siete hombres me salieron al camino con espadas y dagas desnudas, y era gente de galeras.

Aunque afirmaba no tener miedo — «no temo a nadie»—y estar dispuesto a sacar a la luz todas las vellaquerías del auditor, a quien suponía (aunque sin pruebas que lo confirmasen) detrás de ese fallido intento, no dudaba en dar gracias a Dios por haber «salido de aquí». Pese a afirmar que no fue poco lo averiguado, lo cierto es que no logró recabar información concreta - pruebas, testigos comprometidos, testimonios sólidos—, más allá de vagas generalidades:

ha avido cosas que no llevaban ni principio ni fin, ni talle de raçón, y todo ello so capa de justicia, y todo el fin y paradero de todo es y a sido coger dineros de inocentes.

Don Alonso no inició procedimiento alguno contra el auditor, bien porque lo averiguado le pareció - de hecho lo era - poco relevante, bien porque se desinteresó de tal cuestión; no en vano era un hombre del que, sin dudar de su honradez, todos criticaban la falta de control sobre sus subordinados, hasta el punto que delegaba gran parte de sus responsabilidades en «letrados y escribanos de quienes acá y en Sevilla corre mala fama, y él se fía en ellos y en lo que le dicen». Esa falta de supervisión era, sin duda, una de las razones del desorden que tanto había denunciado Butquens, de la propagación de las malas prácticas.

Dos meses más tarde retomaría la investigación Alday, quien reconocía sin ambages que hasta entonces se habían hecho pocas diligencias, aunque había indicios, y «más que indicios» de la actividad delictiva de Alcázar de Heredia. Comisionado por el rey para seguir las causas incoadas por el embargo contra los extranjeros, el regente confiaba en que una vez finalizados los procedimientos judiciales en curso estaría en condiciones de averiguar lo sucedido «con mucho número de testigos». Para hacerlo, solicitaba al monarca le otorgase «particular comisión». Entretanto llegaba una respuesta real, continuó acumulando pruebas contra la actuación del auditor, quien a ojos vista se había enriquecido ilícitamente. Obtenía dinero tanto de los culpados «como de los que no lo son». Había defraudado a la Real Hacienda y había contribuido a entorpecer un embargo que pretendía castigar a los enemigos y fomentar el comercio con quienes no lo eran. En definitiva, su codicia, su deslealtad, siempre movida por el dinero, había provocado el efecto contrario, por cuanto: 
el rebelde que ha sabido con él negociar ha quedado sin la pena que merece, porque lo ha dado por libre, y el que no está culpado ha temido su rigor y malos tratamientos ${ }^{23}$.

Fruto de esa actitud, Alday auguraba, en plena coincidencia con Butquens, el fracaso de aquella política en la que tantos esfuerzos se habían invertido; afirmaba que los extranjeros, ofendidos y agraviados, dejarán de venir a tratar a estos reinos, «porque no pueden tener tantas ganancias que basten a suplir lo mucho que pechan». El acoso al que jueces y comisionados como el auditor les someten es tal que no resulta sorprendente que estas naciones estén «indignadas y poco afectas al servicio de Su Majestad». Consideraba, además, que la responsabilidad de lo sucedido recaía en la inapropiada elección de los servidores de la monarquía; pedía por ello que quienes se eligiesen para el desempeño de esos cargos fuesen personas de satisfacción y de plena confianza:

debe VM poner remedio excusando todo lo que fuere posible juezes de comisión, y quando esta sea necesaria, elegir persona de quien tenga entera satisfacción de que pondrá su cuidado en cumplir con el intento de VM y con su conciencia y no en aprovecharse con agravio de tantos como en este pueblo ay, porque por una parte veo que no se trata del servicio de VM, ni a éste se atiende ni se cumple en cosa ninguna, y por otra que son tantas las ofensas y malos tratamientos, que me obligan a representarlos a VM por lo mucho que importa su remedio.

Las quejas contra el auditor eran tantas y las pruebas que Alday iba reuniendo tan contundentes que confiesa - a mediados de mayo - que estuvo determinado de prenderle; estimaba el regente que no se sentía seguro, «mayormente haviendo comenzado a desviar testigos que le pueden ofender, a los quales si con algún rigor se toma, los dichos dirán la verdad». No lo hizo a la espera de la comisión real, que se retrasaba. El catálogo de delitos que sospechaba había cometido era tan extenso como variado. El oficio que ocupaba le había permitido cobrar derechos abusivos por tomar declaración en los pleitos que seguía: «de tomarles las confesiones y recibir tres o quatro testigos en su descargo, él y sus ministros les han llevado a cien reales, a ciento y cinquenta las más vezes». Esos derechos se estimaban en solo cuatro. En tantos pleitos como se habían abierto y «siendo las confesiones tantas como han sido», el provecho que obtuvo fue mucho. Solo en la ciudad de Sevilla - a las que habría que añadir las causas que sustanció en Cádiz, Sanlúcar y el Puerto de Santa María— había movido más de 350 pleitos, por el método de encausar a una sola persona tantas veces como piezas de mercancías le perteneciesen de diferentes navíos: «porque si en diez

23 AGS, Estado, leg. 184, expediente 200. 
navíos pertenecían algunas piezas a una persona, tantos pleitos se le hazían». Había creado una trama delictiva basada en la dependencia de quienes estaban a su cargo, sobre todo oficiales y escribanos, con quienes se repartía los frutos de sus tropelías. Y por ello muy difícil de romper.

Quienes habían sido perjudicados por esa actitud no se atrevían a declarar, por cuanto el auditor tenía comisión real para juzgar esos litigios. El miedo a multas más severas, a sentencias más rigurosas, impedía que se aportasen pruebas en su contra. Reiteraba Alday que una vez falladas las causas, «los ofendidos que no se atreven a dezir los agravios que les ha hecho, dirán la verdad sin ocultarla como agora lo hazen». Víctimas de sus excesos eran también los mercaderes - tanto flamencos como españoles - que comerciaban con el norte de Europa. Maestres y marineros detenidos por el embargo fueron quienes en mayor medida sufrieron sus abusos, no exentos de violencia, tanto verbal como física. Al maestre del navío San Pedro, al que había apresado pese a ser natural de Hamburgo, lo había tratado con palabras tan feas que «quando fuera galeote pudiera quedar con quexa, siendo hombre hidalgo y de padres honrados, aunque pobres». Su objetivo no era descubrir la verdad, sino obtener las confesiones que le interesaban:

haziéndoles muchas amenazas que si no dezían a su propósito los echaría en galeras, dándoles de moxicones y de cabeçadas en las paredes, de manera que amedrentados destos malos tratamientos han confesado lo que él ha querido [...] ha dado tormentos y hecho confesar lo que a él estaba bien, siendo lo contrario verdad.

La tortura, que ya había denunciado Butquens, fue aplicada por el auditor y sus secuaces no solo en las tripulaciones embargadas, sino también antes del embargo, en las de las presas capturadas por las galeras que corrían la costa. En ninguno de los autos incoados constaba tal práctica, «debiendo de constar». Alcázar de Heredia, a decir de Alday, fue un comisionado que en modo alguno se ajustó a las rigurosas instrucciones dadas por el monarca para llevar a cabo el embargo (López Martín, 2005, p. 8). Uno de esos ministros reales contra los que tanto se había clamado, y se seguiría haciendo. Su incumplimiento fue flagrante y continuo. Al contrario de lo que se había ordenado, no procedió a inventariar las mercancías que portaban los navíos embargados; y todo «por tener ocasión de poderse aprovechar» ${ }^{24}$. Excediéndose en su comisión, había embargado mercaderías de navíos que llegaron a las costas andaluzas hasta dos y tres meses antes de que se decretase el embargo. Ya realizado, procedió asimismo contra las de los navíos que el propio Alday había dado por libres. Se le acusaba incluso de que sus hombres habían dado muerte a dos marineros y herido a varios.

$24 \quad$ «Inventario de cada nao, con declaración de su porte y calidad, y de las mercaderías y xarcias y municiones, bastimentos y artillería que en cada una se halló». 
Fueron las tripulaciones, los propietarios y los correspondientes de las embarcaciones liberadas por no ser de partes rebeldes y enemigas, quienes en mayor medida sufrieron la codicia de Alcázar de Heredia. Además del maltrato y el cobro de tasas excesivas, recaudó grandes cantidades de dinero por desembargarlas. A 15 o 16 de ellas, de partes seguras, llevó a los maestres 350 ducados. No fueron las cantidades más elevadas que por ese motivo se embolsó. A dos navíos de Hamburgo, que Alday no identifica, les cobró de 600 a 800 ducados. Pero el ejemplo que menciona el regente con más detalle es el de lo ocurrido al navío Santiago. A su maestre, Jacob Pietersen, que viajaba con pasaporte del archiduque, era católico y de «parte segura y no rebelde», le pidió 500 ducados por su desembargo, «los cuales el maestre vino a pedir a los interesados que residían en Sevilla» al no disponer de esa cantidad. Entretanto la conseguía «llegó nueva de Sanlúcar que el navío se había anegado por culpa del dicho Auditor, porque le hizo quitar el timón y la gente que tenía». El valor de lo perdido, navío y mercadería, se estimó en 24.000 ducados. Asimismo se decía, aunque no había podido probarse, que «por dineros» había desembargado navíos holandeses.

Sus actuaciones delictivas también afectaban a la Hacienda. Si uno de los objetivos confesos del embargo había sido conseguir recursos para las arcas reales con la venta de navíos, mercancías y bastimentos confiscados, el auditor se apropió a su vez de parte de lo que correspondía a Su Majestad, «ocultamente, de noche y con mucho recato». Así, según varios testigos, sus hombres entraron en el navío Sansón, embargado en el puerto de Sanlúcar y desembarcaron parte de su valiosa carga: cuarenta pacas de ropa de Flandes y cuatro grandes cofres que contenían olandas. En su lugar metieron lienzo francés, «falseadas las marcas». Una acción que suponía un grave fraude, por cuanto «las dichas quarenta pacas pudieran pertenecer a Vuestra Majestad por ser de rebeldes».

Todavía a mediados de mayo se mostraba Alday esperanzado en que los testigos se decidieran a colaborar en una investigación que aún no contaba con la aprobación real. Sostenía que era lo probado poco, «respecto a lo que se probará». La primera parte de esa afirmación era cierta. La mayor parte de las acusaciones se sustentaban en sospechas sin más fundamento que aquello que unos testigos habían oído decir o que eran asuntos de general conocimiento. Ningún argumento probatorio. Ninguna prueba definitiva. Incluso la acusación acerca del navío Santiago parecía, era de hecho, especulativa. No obstante, su insistencia hizo que se le otorgase la comisión que demandó para continuar la investigación. La carta real se emitió el 8 de julio, nueve meses después de realizado el embargo. En ella, se le pedía que averiguase «muy particularmente todo lo que hubiere pasado acerca de los escesos y cosas indebidas $\rangle^{25}$.

AGS, Estado, leg. 184, expediente 263. 
La información que recabase debía enviarla cerrada y sellada al Consejo de Estado. Quizás demasiado tarde, porque quienes habían sufrido los agravios y molestias del auditor — del que calculaba Alday se había embolsado más de 20.000 ducados — ya habían desaparecido de las costas peninsulares. Tampoco, obviamente, se contaría con el testimonio de los rebeldes que con sobornos habían conseguido liberarse.

Dicha comisión también afectaba a otro personaje que no se caracterizaba por su integridad. Contra el doctor Castañeda, juez de comisión contra los que sacan dineros del reino, se había abierto investigación a raíz del maltrato que había dispensado a los propietarios de dos navíos de Bretaña, embargados por el Duque de Medina Sidonia. Las mercancías que portaban, depositadas en un almacén, habían sido sacadas por sus dueños, «por su autoridad», por lo que habían sido encarcelados «mucho tiempo». La mayor parte de ellas se había vendido en las gradas de la ciudad, en pública almoneda, aunque con quejas de los interesados por el bajo precio al que se entregaron. Los bretones denunciaron la actuación de Castañeda, a quien acusaban de permitir la venta de sus bienes «a menos precio», de impedirles acceder a las pujas, de condenar a muerte y «perdimiento de bienes» a los franceses ausentes e imponer excesivas multas a quienes se presentaron, en prisión por no poderlas afrontar ${ }^{26}$. Castañeda había procedido con extrema violencia contra los franceses:

llegó a su casa acompañado de corchetes y soldados con sus arcabuces y mechas encendidas, a las dos de la mañana, con tanto ruido y alboroto que, entendiendo los querían saquear, se arrojaron algunos de las ventanas y quedaron maltratados [...] tratándolos ansimismo con tan malas palabras que las menos malas fueron enemigos, herejes y vasallos del Vandoma herege, y con tan malas obras que esa noche los corchetes y soldados hurtaron en las casas que entraron mucha cantidad de hazienda y dineros ${ }^{27}$.

Los despropósitos del juez ponían en riesgo la paz que menos de un año antes se había firmado con Francia; ante las quejas recibidas, se ordenó a Alday la inmediata puesta en libertad de los franceses, con la imposición de una fianza de no ausentarse hasta la finalización de los autos ${ }^{28}$. Desde la corte se instó al regente a continuar la

$26 \quad$ Una práctica habitual que proporcionaba grandes beneficios a quienes adquirían esas mercancías tras un embargo. En la decisión de Castañeda de ajustarlas a un valor más bajo del que tenían subyacía la acusación de una connivencia con los compradores que le reportaría sustanciosas ganancias y resultarían a la postre los grandes beneficiados del embargo. No obstante, Alday afirmaba que el procedimiento había sido correcto y que «si los dueños de la dicha hazienda la quisieran, se les ubiera dado por el tanto, como también lo es que con los pregones que se dieron no pudieron quedar ofendidos». Ibídem, expediente 201. No consideraba, por tanto, que la queja interpuesta contra Castañeda fuese cierta.

$27 \quad$ AGS, Estado, leg. 184, expediente 201.

28 El rey de Francia envió a la corte de Madrid a Juan de Sanserre para tratar de la liberación de los navíos bretones. Ibídem, expediente 262 . 
investigación hasta «entender la verdad» y tomar la resolución que convenga. Una persona confidente se encargó de averiguar en Sanlúcar la conducta del doctor Castañeda, del que «según se dice» había recibido cohechos por valor de cinco mil ducados. Al igual que sucedía con el auditor, los testigos no se atrevían a decir la verdad, a declarar, porque siendo «teniente de este pueblo [...] les podrá ofender». Aunque no aportaba pruebas de su actuación, sostenía Alday que todas las quejas que contra él se hacían eran ciertas: liberación de quienes debían ser sancionados, condenas sin fundamento, con testigos de «poco crédito» e imposición de multas excesivas — de hasta veinte mil y treinta mil ducados_-, imposibles de ser abonadas. Y todo ello para justificar un buen servicio a Su Majestad, cuyas arcas nunca podrían ingresar esos dineros.

\section{Conclusiones}

Actuaciones como las de Castañeda y Alcázar de Heredia no eran meros actos delictivos, sino prácticas consideradas moralmente censurables e impropias de los ministros reales; Alday lo manifestaba con total claridad cuando afirmaba que «ninguna culpa puede haber en nosotros más digna de castigo, por los grandes daños que resultan contra el bien público y servicio de Vuestra Majestad». Y debían ser perseguidas por cuanto suponían que se incumplían las exigencias de integridad a las que estaban obligados los oficiales reales ${ }^{29}$ (Gómez González, 2018, p. 104). No conocemos el resultado final de estas pesquisas, si Alday consiguió probar las acusaciones y si tales acciones fueron castigadas ${ }^{30}$. Pese a ello, este episodio ilustra a la perfección la ineficacia de los mecanismos preventivos y de control en los que tanto se había hecho hincapié (Ponce, 2018, p. 341). La lentitud de la respuesta real y la consiguiente dificultad o imposibilidad para probar los hechos de los que se sospechaba por parte de leales servidores reales, como Butquens primero y Alday después, así lo ponen de relieve.

Coyunturas como la del embargo de 1598 fueron ocasiones propicias para la creación y desarrollo de redes como la tejida por Alcázar de Heredia, un individuo, al igual que Castañeda, con poder y capacidad de intimidación suficientes para implicar en sus andanzas a un considerable número de individuos — guardas, escribanos, oficiales, soldados-, esos ministros inferiores que, pese a lucrarse, no eran los responsables últimos de una situación que tanto perjudicaba, como señalara Butquens, a la reputación de la monarquía. Ministros avariciosos y codiciosos —en acertada

29 Aunque no todas lo fueron. También se había acusado a Pedro de Zubiaur y sus hombres de robos de mercancías y diversos actos violentos, con resultado de dos muertos y varios heridos, así como de robo de mercancías de navíos embargados. Sin embargo, esas denuncias nunca se investigaron.

30 Esperamos que el Archivo Ducal de Medina Sidonia, en el que actualmente trabajamos, pueda arrojar alguna luz sobre estos acontecimientos. 
expresión de Saavedra Fajardo-, solo atentos a engrandecerse y fabricar su fortuna eran "peligrosos en los cargos». Con individuos como ellos, un estado no podía estar bien gobernado. Y sobre todo ponía en riesgo, cuando no condenaba al fracaso, sus políticas porque «ninguna acción sale como conviene cuando se atraviesan intereses propios» (Saavedra Fajardo, 1988, pp. 360-364). Y por ello era necesario, vital, extremar la prudencia en los nombramientos y la vigilancia en el desempeño de las funciones, con independencia del lugar que se ocupara en la jerarquía. En este sentido, cabe señalar que en el fecundo e inacabado debate en torno a la oportunidad y resultados de los embargos, entre quienes han defendido su inoperancia y quienes han insistido en su eficacia, el daño que infringieron al comercio holandés y los obstáculos que supusieron para la libre circulación de mercancías, por más que no consiguiesen doblegar su potencial, apenas se hace referencia a la incidencia de las malas prácticas, los abusos y las extorsiones, tan frecuentes en situaciones como la reseñada en este trabajo (Gómez Centurión, 1988, p. 280 y ss.; Israel, 1988, pp. 89-106; Herrero, 2007, pp. 13-31; Gelabert, 2008, p. 12). Estamos convencidos de que fueron un factor más a tener en cuenta para explicar su limitado alcance para los intereses de la monarquía; y no solo porque se privara a la Real Hacienda de una parte de los recursos que se habían estimado conseguir, sino también porque se puso en riesgo el propósito de fidelizar a quienes, amigos y neutrales, debían sustituir a los holandeses, amén de las pérdidas que ocasionó a los mercaderes — flamencos y españoles — establecidos en Andalucía. Todo ello, como se ha comprobado, fue denunciado, entre otros, por Butquens y Alday. Cierto es que el embargo supuso para las arcas reales unos ingresos que se han estimado solo en Andalucía en unos 250.000 ducados, pero no es menos cierto que esa cifra quedó lejos de las expectativas que se habían generado (López Martín, 2005, p. 10).

En el estado actual de las investigaciones resulta imposible calibrar cuál fue el impacto del fraude, de los cohechos y, en definitiva, de la corrupción y las malas prácticas en esos resultados y, en menor medida, si cabe, como afectó al comercio holandés. No faltan testimonios que avalan, también en este caso, sus limitados efectos: avisos a las naos holandesas para que evitasen entrar en puerto, liberación de embargados o trabas para embargar haciendas de tripulaciones y de sus correspondientes. Sí creemos, no obstante, que tanto en un caso como en otro, sus consecuencias fueron similares a otros inconvenientes, tales como la falta de coordinación de los comisionados, el incumplimiento de las reales órdenes, la escasez de recursos materiales y humanos o los retrasos en la resolución de un embargo para cuya resolución se pedía brevedad; aspectos todos ellos que provocaron un incremento de los gastos por guarda y custodia y un deterioro de los navíos apresados, tal que, como decía Avellaneda con evidente exageración, «no habrá quien dé un real por ellos». La insistencia en disponer de ministros fieles, preparados y comprometidos, tal como se ha puesto de relieve 
en los ejemplos citados en la primera parte de este trabajo, no es sino una muestra de un mal que se había convertido en endémico. Es en esa reiteración y en el análisis de casuísticas concretas donde se podrá determinar cuáles fueron las dimensiones reales de unos comportamientos que resultarían, a pesar de los esfuerzos desplegados, imposibles de erradicar.

\section{AGRADECIMIENTOS}

Este trabajo se ha elaborado con la cobertura del Grupo de Estudios de Historia Social del Occidente Moderno Peninsular (GEHSOMP). 


\section{Bibliografía}

Alloza APARICIO, Ángel (2009) «Portuguese Contraband and the closure of the Iberian markets, 1621-1640. The economic roots of an anti-Habsburg sentiment», E-Journal of Portuguese History, 7, pp. 1-18.

Alloza APARICIO, Ángel (2012), «Guerra económica y proteccionismo en la Europa del siglo XVII: el decreto de Gauna a la luz de los documentos contables», Tiempos Modernos, 24, pp. 1-34.

Alloza APARICIO, Ángel y CÁRCEles de GeA, Beatriz (2009), Comercio y riqueza en el siglo XVII: estudios sobre cultura, politica y pensamiento económico, Madrid, CSIC.

AndúJar CASTILlo, Francisco y Ponce Leiva, Pilar (2018), «Introducción», en Debates sobre la corrupción en el mundo ibérico. Siglos XVI-XVIII, Alicante, Biblioteca Virtual Miguel de Cervantes, pp. 11-14.

ANDÚJAR, Francisco; Feros, Antonio y Ponce, Pilar (2017), «Corrupción y mecanismos de control en la Monarquía Hispánica: una revisión crítica», Tiempos Modernos, 35, pp. 284-311.

Baltar, Juan Francisco (1998), Las Juntas de Gobierno en la Monarquía Hispánica (siglos XVI-XVII), Madrid, Centro de Estudios Políticos y Constitucionales.

Barrientos Grandón, Javier (2018), «El oficio y su proyección en el lenguaje de las residencias: Bueno, recto y limpio juez», en Andujar Castillo, Francisco y Ponce Leiva, Pilar (coords.), Debates sobre la corrupción en el mundo ibérico. Siglos XVI-XVIII, Alicante, Biblioteca Virtual Miguel de Cervantes, pp. 83-101.

ECHEVARría BACIgALupe, Miguel Ángel (1985), «Examen de una polémica sobre los intercambios exteriores a principios del siglo XVII», Studia Historica. Historia Moderna, pp. 119-142.

Gelabert, Juan Eloy (2007), «Entre embargo general y libre comercio. Las relaciones mercantiles entre Francia y España de 1598 a 1609», Obradoiro de Historia Moderna, 16, pp. 65-90.

Gelabert, Juan Eloy (2008), «Guerra y coyuntura fiscal: el embargo general de 1598», IX Congreso AEHE, pp. 1-23.

Gómez CENTURIón, Carlos (1986), «Las relaciones hispano-hanseáticas durante el reinado de Felipe II», Revista de Historia Naval, 15, pp. 65-84.

Gómez Centurión, Carlos (1988), Felipe II, la empresa de Inglaterra y el comercio septentrional (1566-1609), Madrid, Editorial Naval.

Gómez GonzÁLEZ, Inés (2018), «Corrupción moral versus corrupción profesional: percepción, persecución y castigo en el Antiguo Régimen», en Andujar Castillo, Francisco y Ponce Leiva, Pilar (coords.), Debates sobre la corrupción en el 
mundo ibérico. Siglos XVI-XVIII, Alicante, Biblioteca Virtual Miguel de Cervantes, pp. 103-114.

Herrero, Manuel (2007), «Hegemonía y mercados: el impacto de la guerra económica en la posición internacional de la Monarquía Hispánica», en González Mezquida, María Luz (ed.), Estudios de Historia Moderna. Contextos, teorías y prácticas historiográficas, Mar del Plata, EUDEM, pp. 13-31.

IsRAel, Jonathan I. (1985), «Manuel López Pereira of Amsterdam, Antwerp and Madrid: Jew, New Christian an advisor to the Conde-Duque de Olivares», Studia Rosenthaliana, 19, 2, pp. 109-126.

ISRAEL, Jonathan I. (1988), «España, los embargos españoles y la lucha por el dominio del comercio mundial, 1585-1648», Revista de Historia Naval, 6, 23, pp. 89-106.

ISRAEL, Jonathan I. (1996), «La guerra económica y la Monarquía Hispánica en el siglo XVII», en Ruiz Martín, Felipe (coord.), La proyección europea de la Monarquía Hispánica, Madrid, Universidad Complutense, pp. 39-48.

López MARTín, Ignacio (2005), «Entre la guerra económica y la persuasión diplomática: el comercio mediterráneo como moneda de cambio hispanoneerlandés (1574-1609)», Cahiers de la Méditerranée, 71, pp. 2-20

Luxán Menéndez, Santiago (1989), «Los funcionarios del Consejo de Portugal (1580-1640)», Cuadernos de Investigación Histórica, 12, pp. 197-228.

Ponce LeIva, Pilar (2018), «Mecanismos de control en la monarquía hispánica y su discutida eficacia», en Andujar Castillo, Francisco y Ponce Leiva, Pilar (coords.), Debates sobre la corrupción en el mundo ibérico. Siglos XVI-XVIII, Alicante, Biblioteca Virtual Miguel de Cervantes, pp. 341-352.

Pulido Bueno, Ildefonso (1993), Almojarifazgos y comercio exterior en Andalucía durante la época mercantilista, 1526-1740, Huelva, Artes gráficas andaluzas.

RAU, Viginia (1951), A exploraçao e o comercio do sal de Setúbal. Estudo de Historia Economica, Lisboa, Bertrand.

Rodríguez GraJERA, Alfonso (2015), «Un episodio de la guerra económica hispanoneerlandesa. El proyecto y la comisión de Joachim Butquens (1598-1599)». Revista de Estudios Extremeños LXXI, III, pp. 1809-1842.

RuIz IBÁÑEZ, José Javier (2005), «Bellum Omnium contra omnes. Las posibilidades y contradicciones por parte de la Monarquía Hispánica en la década de 1590», Studia Historica. Historia Moderna, pp. 85-109.

SaAvedra Fajardo, Diego (1988), Empresas Políticas (ed. Francisco Javier Díez de Revenga), Madrid, Planeta.

Schaub, Jean F. (2001), Le Portugal au temps du Comte-Duc d'Olivares (1621-1640), Madrid, Casa de Velázquez. 
